\title{
Integração social ou novas relações entre Estado e sociedade no Brasil
}

\author{
ROBERTO SMITH \\ e AÉCIO ALVES DE OLIVEIRA
}

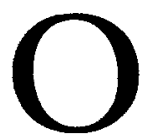

TEMA DA INTEGRAÇÃo é parte do debate a respeito do desenvolvimento do país, notadamente no pós-Guerra, quando colocado em termos da tendência à generalização das relações do moderno capitalismo, no quadro de sua estrutura produtiva, social e regional. Salm et al., a esse respeito, enfatizam que o capitalismo no Brasil vem se caracterizando mais pela integração, tendo por centro o mercado de trabalho, do que por um quadro de exclusão, resultante de supostas razões de insuficiências dinâmicas. Em termos conceituais, o tema da integração articula uma tendência crescente da produtividade, decorrente da competitividade, que implicaria diminuição de disparidades intersetoriais e inter-regionais e, ao mesmo tempo, promoveria encadeamentos na matriz produtiva, nivelando as diferenças, referenciando todo o processo de acumulação. $\mathrm{Na}$ verdade, integração incorpora tanto o mercado de trabalho quanto a estrutura produtiva, bem como suas implicaçóes sobre a distribuição de renda. A integração, na vertente da divisão inter-regional do trabalho, foi amplamente tratada por Oliveira (1970), Carleial (1989) e outros, tendo a questão suscitado debates. Ao longo da década de 80, contudo, o debate da integração passa a abranger um espectro mais amplo imposto pela globalização. Coloca em destaque o relativo grau de fechamento da economia brasileira no quadro da competitividade internacional e os novos paradigmas tecnológicos e de processos de trabalho que vão se forjando. A agenda de inserção econômica na ordem competitiva internacional acentua as disparidades internacionais, principalmente em países como o Brasil que, à mercê do fenômeno da financeirizaçáo ampliada do capital, se vêem projetados num quadro estagflacionista e de debilitação estatal. As determinaçôes externas impostas pela globalização, não desprezadas as especificidades domésticas, podem ser visualizadas no quadro de semelhanças e regularidades envolvendo os países da América Latina. Regularidades essas já verificadas com o processo de penetração do capital industrial estrangeiro a partir de meados dos $\mathbf{5 0}$ ou, ainda antes, com o modelo de substituição de importaçóes. 
A presente marcha da integração globalizante, e das formas nacionais de ajustamentos endógenos, vem gerando processos que requerem entendimento e controle político e social. Isso no sentido da explicitação de políticas democráticas que assegurem integração social e territorial, bem como diminuam a amplitude da desigualdade de oportunidades para a população.

No quadro atual da estrutura social brasileira percebe-se, pelo menos, dois processos importantes para o debate a respeito da construção de uma sociedade mais justa e menos excludente - dotada, minimamente, de integração social e territorial. Um relaciona-se à transiģão demográfica pela qual passa o país, com radical transformação de sua estrutura populacional; o outro, centrase na dinâmica recente da distribuição e concentração da renda no país, principalmente a partir da década de 80. Trata-se de fenômenos que apresentam vinculaçóes, ambos resultantes de construção sociàl, política e econômica, nem sempre decorrentes de intencionalidade explícita, e que representam uma herança do presente que se projeta para o futuro, enquanto restriçóes e carências passíveis de reversão ou de se tornarem ainda mais agudas. Isto significa que o sentido de integração social, compreendendo melhoria de oportunidades, methores condiçóes de vida, participação social e política, não se encontra dado, podendo se tornar mais ou menos crítico a partir do quadro atual em que se delineam projetos para o país.

A transifaño demográfica vincula-se fortemente a dois processos temporalmente defasados. Um que se traduz na queda tendencial da taxa de mortalidade, a partir da década de 40 , situado dentro de padróes internacionais de dissemina- çáo de melhores condiçốes sanitárias e de saúde. $O$ outro, a partir da década de 60 , marcado pela queda da taxa de natalidade.

A taxa de mortalidade, que em 1900 era da ordem de 27 por mil habitantes, caiu lentamente até 1940 para 12,5 por mil. Em 1990 atingiu 7,5 por mil e tende a se estabilizar num patamar de 7 por mil na virada do século.

A taxa de natalidade no Brasil, na primeira década deste século, era de 45,2 por mil habitantes situando-se, até 1960 , em cerca de 41,5 por mil. Em 1990 a taxa havia caído para 24,5, tendo sido projetada para o ano 2020 da ordem de 15,2 por mil habitantes. A queda na taxa de natalidade decorre da diminuição da taxa de fecundidade, que mede o número de filhos que as mulheres têm em média durante o período convencionado de vida fértil. A utilização de métodos anticoncepcionais e a interrupção da gravidez atuam sobre essa componente. A disseminaçáo do uso da pílula anticoncepcional e de outros métodos anticonceptivos foram mais recentemente sobrepostos pelo avanço da prática da esterilização feminina que, por ser irreversível, vem afetando a estrutura demográfica brasileira de forma permanente. 
Assiste-se no século $\mathrm{XX}$, portanto, a uma ruptura com os padróes demográficos vigentes em sociedades denominadas arcaicas ou tradicionais, isto é, aquelas dotadas de elevadas taxas vitais e crescimento vegetativo lento. Essa ruptura se dá na direção de uma explosão demográfica decorrente primeiramente da queda acentuada da taxa de mortalidade, que desorientou os planejadores urbanos na década de 60 , seguida por uma queda do crescimento vegetativo, resultante da retraçáo na taxa de natalidade, projetando uma tendência de equilíbrio demográfico, o qual, em termos de cifras parece se aproximar daquele equilíbrio atingido pelos países desenvolvidos. No Brasil os padróes demográficos médios encerram diferenças marcantes segundo as partiçóes analíticas adotadas em termos de regióes - rural e urbana - e sociais envolvendo renda, educação etc. (1)

Em resumo, o fenômeno da transiçāo demográfica aponta para:

- a necessidade de se retomar a agenda de discussóes a respeito da transiçáo demográfica no sentido de recuperar algum controle social, ético e político sobre o processo;

- a importância da inclusão dos efeitos resultantes da transição demográfica pela qual vem passando o país, e da necessidade de incorporar esses efeitos nas análises prospectivas e na programaçáo de uma possível retomada do planejamento no país;

- a importância das modificações nas configurações regionais e urbanas em termos de crescimento e estrutura populacional. A população do Nordeste, por exemplo, vem crescendo a taxas inferiores às da população brasileira, e esse aspecto não é explicado apenas pela emigração. Tal fato significa adicionalmente que qualquer retomada de fluxos migratórios a partir do Nordeste para outras regiōes pode configurar uma perda relativa mais intensa. Isto, contudo, dependerá de fatores desencadeadores da mobilidade populacional, comumente mais atuantes em épocas que conjugam efeitos adversos como, por exemplo, a seca, e crescimento econômico generalizado e persistente, o que não se verificou desde a década de 80 .

- o abrandamento da intensidade de crescimento das populaçóes urbanas e o conseqüente arrefecimento de pressóes sobre o Setor Público dentro do horizonte temporal dos próximos 20 anos. Nesse sentido, o momento presente aponta estrategicamente para a necessidade premente de açóes governamentais destinadas a recuperar o enorme passivo acumulado de atendimento, notadamente em educação e saúde. Isso somente poderá se tornar exeqüível dentro de uma política adequada e oportuna que contemple as características e especificidades regionais, estaduais e mesmo municipais. 


\section{Aspectos da distribuição de renda no país}

A tabela 1 é bastante reveladora do quadro distributivo brasileiro nestes últimos trinta anos. Em 1960, a renda apropriada pelos 10\% mais ricos era 34 vezes superior à renda apropriada pelos $10 \%$ mais pobres. Em 1990 esta proporção se eleva para 78 vezes. Vale frisar que o índice de Gini capta melhor as modificaçóes na estrutura da renda afetando as camadas de renda média, enquanto a relação entre o primeiro e último decis da renda capta melhor as modificaçōes que ocorrem nos extremos da distribuição.

A dinâmica da concentração de renda no Brasil tem se manifestado de forma intensa durante a década de 60 , com incremento na década de 70 e recrudecimento nos anos 80 . A concentração de renda na década de 60 apresentou, contudo, características distintas daquela observada a partir dos 80. Naquela década o crescimento do grau de desigualdade afetou mais intensamente os segmentos de renda média da população. Na década de $80 \mathrm{em}$ diante os segmentos mais fortemente afetados encontram-se situados nas camadas de renda baixa. De qualquer maneira, percebe-se, ao longo de todo o período que o processo de concentração de renda tem penalizado sistematicamente os mais pobres, o que fundamenta as estatísticas recentes sobre o tamanho da indigência no país.

Tabela 1

Brasil: Evolução dos índices de concentração de renda

\begin{tabular}{ccccc}
\hline Ano & Coef. Gini & índice & $10+/ 10-$ & Índice \\
\hline 1960 & 0,50 & 100 & 34 & 100 \\
1970 & 0,60 & 120 & 40 & 118 \\
1980 & 0,59 & 118 & 47 & 138 \\
1990 & 0,63 & 126 & 78 & 229 \\
\hline
\end{tabular}

Fonte: Barros Mendonça \& Rocha, 1993.

O Brasil apresenta ainda, em termos comparativos, o mais elevado grau de desigualdade de renda dentre aqueles países que dispóem de estatísticas mensurando o fenômeno. Tomando a medida de desigualdade de renda estabelecida pela relação entre a proporção da renda total apropriada pelos $10 \%$ mais ricos e a proporção da renda apropriada pelos $\mathbf{4 0 \%}$ mais pobres é possível constatar o quadro relativo apresentado a seguir.

Em geral as estatísticas de desigualdade de renda utilizadas no Brasil póem à mostra, principalmente, diferenciais de salários, uma vez que o conceito de renda captado pelos levantamentos (Pnad e Censos) não incorpora os ganhos financeiros e patrimoniais mais expressivos (2). Estes últimos ganhos expandiram-se com o processo inflacionário e em função das políticas de ajustamento 
postas em prática ao longo da década de 80 e início de 90 . Na realidade, os diferenciais de salários apenas revelam, mas não explicam a causa da desigualdade.

Tabela 2

Quadro comparativo internacional de desigualdade de renda

\begin{tabular}{llll}
\hline País & $10+/ 40-$ & País & $10+/ 40-$ \\
\hline Ásia & & Países desenvolvidos & \\
Bangladesh & 1,1 & Austrália & 1,6 \\
Índia & 1,4 & Canadá & 1,3 \\
Indonésia & 1,3 & Dinamarca & 1,3 \\
Malásia & 2,5 & Finlândia & 1,2 \\
Paquistão & 1,6 & Holanda & 1,2 \\
Filipinas & 2,1 & Hungria & 0,7 \\
Cingapura & 2,3 & Itália & 1,3 \\
Sri-Lanka & 3,3 & Nova Zelândia & 1,8 \\
África & & Polônia & 0,9 \\
Botswana & 4,8 & Espanha & 1,3 \\
Gana & 1,7 & Suécia & 1,0 \\
Costa do Martim & 2,8 & Suíça & 1,8 \\
Marrocos & 1,1 & Estados Unidos & 1,6 \\
América Latina/Caribe & & lugoslávia & 1,6 \\
Brasil a & 5,8 & & \\
Colômbia & 2,8 & & \\
Costa Rica & 3,3 & & \\
Jamaica & 2,2 & & \\
Peru & 2,8 & & \\
Venezuela & 2,4 & & \\
\hline
\end{tabular}

Fonte: Human development report, U.N., 1991.

No entanto é possível fazer uma inferência, a partir do que se denomina de distribuição funcional da renda, a fim de estabelecer uma conexão entre desigualdade e pobreza. Ao longo da chamada década estagnada esta conexão revelou-se mais visível, pois se deu no âmbito de um período sem crescimento econômico, quando cresceram tanto as rendas financeiras quanto o lucro, em detrimento da diminuição da parcela salarial, isto é, da participação da massa de salários na renda nacional. Segundo estimativas do Dieese, a participação dos salários na renda nacional, no início dos anos 80 , era de aproximadamente $50 \%$, decrescendo para menos de 35\%, em 1991.

Dois são os aspectos a serem analisados no âmbito da desigualdade de renda:

- as causas da desigualdade;

- o porquê da elevada amplitude entre a renda dos segmentos mais baixos e mais elevados da renda.

Existem dois movimentos a serem destacados: o de desigualdade da renda, aferido pelos indicadores de concentração; e o de empobrecimento da população 
ativa (pessoas trabalhando e auferindo rendimentos), que se encontra vinculado à queda da sua renda real média ao longo do tempo. Com a tendência declinante da renda real média ocorrem tensões e acomơdações nas quais distintos estratos de renda podem ganhar ou perder, alterando os perfis de distribuição. Entram em jogo aí, principalmente, as formas organizadas de defesa do nível de salários, que variam segundo a atuação sindical nos setores da economia; o maior ou menor nível de especialização dos assalariados etc. O movimento de concentração dos anos 80 é observado diante da perda de renda real da população ativa. Nos anos de 1990 a 1992 a desigualdade de salários aponta para melhoria na distribuição, mas isso se dá porque ocorre perda salarial mais intensa dos assalariados com maiores rendimentos, em relação aos assalariados com menores rendimentos, dentro de um quadro ainda mais drástico de queda da renda real média da população ativa. As séries que mostram o comportamento dos índices reais do PIB, PIB per capita, salário mínimo e salário médio pagos pela indústria paulista são evidenciadas na tabela 3 .

Tabela 3

Índices de evolução do PIB, PIB per capita, salário mínimo e salário médio na indústria paulista

\begin{tabular}{rrrrr}
\hline Ano & $\begin{array}{c}\text { PIB } \\
\text { per capita }\end{array}$ & PIB & $\begin{array}{c}\text { Salário } \\
\text { Mínimo }\end{array}$ & $\begin{array}{c}\text { Salário Indústria } \\
\text { Paulista }\end{array}$ \\
\hline 1970 & 55,3 & 43,7 & 90,3 & ND \\
1971 & 60,1 & 42,7 & 90,4 & ND \\
1972 & 65,7 & 54,5 & 92,7 & ND \\
1973 & 73,1 & 62,1 & 96,3 & ND \\
1974 & 77,2 & 67,1 & 90,8 & 77,0 \\
1975 & 79,3 & 70,6 & 97,0 & 71,8 \\
1976 & 85,4 & 77,9 & 95,5 & 74,8 \\
1977 & 87,7 & 81,7 & 71,1 & 90,0 \\
1978 & 85,8 & 85,8 & 97,9 & 94,6 \\
1979 & 93,7 & 91,6 & 97,5 & 100,0 \\
1980 & 100,0 & 100,0 & 100,0 & 97,3 \\
1981 & 93,7 & 95,5 & 98,7 & 99,1 \\
1982 & 92,4 & 96,1 & 99,1 & 82,9 \\
1983 & 87,6 & 92,7 & 87,9 & 81,4 \\
1984 & 90,4 & 97,6 & 81,2 & 91,9 \\
1985 & 95,7 & 105,4 & 83,9 & 106,8 \\
1986 & 101,1 & 113,4 & 82,3 & 97,0 \\
1987 & 102,7 & 117,4 & 64,1 & 94,9 \\
1988 & 99,9 & 117,3 & 64,2 & 104,1 \\
1989 & 102,0 & 121,2 & 69,7 & 78,7 \\
1990 & 95,7 & 115,8 & 48,0 & 69,2 \\
1991 & 94,9 & 117,2 & 55,1 & 72,1 \\
1992 & 92,3 & 116,1 & 47,3 & \\
\hline
\end{tabular}

Fonte: Ipea

Sabóia, J.L.M. - Evolução do salário mínimo no Brasil

Calculados a partir dos dados da Fiesp - Indicadores Conjunturais 
O quadro da distribuição de renda no Brasil apresenta diferenças regionais expressivas como pode ser visto na tabela 4.

Tabela 4

Índice de Gini - Brasil, Sudeste e Nordeste

\begin{tabular}{cccc}
\hline Ano & Brasil & Sudeste & Nordeste \\
\hline 1981 & 0,583 & 0,569 & 0,577 \\
1983 & 0,600 & 0,586 & 0,595 \\
1984 & 0,599 & 0,588 & 0,585 \\
1985 & 0,609 & 0,594 & 0,605 \\
1986 & 0,602 & 0,589 & 0,587 \\
1987 & 0,611 & 0,591 & 0,622 \\
1988 & 0,629 & 0,607 & 0,639 \\
1989 & 0,647 & 0,628 & 0,653 \\
1990 & 0,620 & 0,598 & 0,631 \\
\hline
\end{tabular}

Fonte: Ipea/Fibge

Rendimento mensal das pessoas de 10 anos ou mais, com rendimentos.

Ao se conjugar a distribuição de renda com variáveis demográficas pode-se constatar que:

- a queda na taxa de fecundidade ocorreu de forma mais intensa nas famílias de renda mais baixa, mesmo a taxa de fecundidade sendo maior nessas famílias. Em 1980 a taxa média de fecundidade para o Brasil era de 4,35. Para as famílias de classes de renda até um $S M$ era de 5,9; de um a três $S M$ era de 4,8. Para as famílias de classe de renda de mais de dez SM caía para apenas 2 (Camarano \& Beltrão, 1989);

- a esperança de vida ao nascer da população masculina é de 52,5 anos (57 para as mulheres) nas famílias de classe de renda de um a três SM e de 67 anos (72,8 para as mulheres) nas famílias de classe de renda de dez e mais SM;

- a taxa de natalidade em 1975/1980 era de 30,7 e-a de mortalidade 6,6 por 1.000 habitantes; a taxa de crescimento era de $2,1 \%$ a.a. Para as famílias com renda até um SM a taxa de natalidade era de 40,3 e a de mortalidade 10,6; a taxa de crescimento de 3,1\% a.a. Para as famílias com renda de dez SM e mais, a taxa de natalidade era de 19,4 e a de mortalidade 5 ; a taxa de crescimento observada era de $-0,3 \%$ a.a.

\section{A crise da economia e do Estado no Brasil e na integração social}

A década de 80 e o início dos anos 90 marcaram um período de estagnação da economia do país, acompanhado de algumas flutuaçōes. É importante chamar 
a atenção de que estagnação não significa ausência de movimento no interior da economia. Pelo contrário, ocorreram reordenaçóes, evidenciando focos de crescimentos localizados, formas específicas de financiamento e adaptaçóes com relação ao comércio internacional através de políticas de créditos e subsídios. Além do mais, ocorreram importantes modificaçōes nos padrōes de consumo de produtos e serviços, vinculados inclusive ao crescimento urbano e à concentração de renda, e abertura de fronteiras agrícola-minerais com repercussóes em nível da distribuiçāo espacial das atividades (Smith, 1991).

Nesse período as modificaçóes ocorridas na divisão espacial do trabalho foram específicas de um quadro de economia estagnada. O setor industrial apresentou papel relativamente neutro no ajustamento espacial da divisão inter-regional do trabalho. Ao mesmo tempo assistiu-se à expansão de setores vinculados à política de geração e economia de divisas, com o surgimento de algumas economias de enclave, autonomizadas e vinculadas internacionalmente, com destaque para alguns produtos agrícolas de exportação, de minérios, álcool e petróleo (Diniz \& Lemos, 1990).

Até 1976 o Brasil tomava empréstimos externos basicamente para investimentos. De 1977 em diante, a dívida externa assume caráter financeiro quando os empréstimos vinculam-se a pagamentos de juros. Tem-se então uma reversão de fluxo de capitais para fora do país, cessando a entrada do que se convencionou chamar de dinbeiro novo. Essa reversão coincidiu com a explosão das taxas de juros internacionais deliberada pelo governo Reagan, acelerando o crescimento financeiro da dívida. No início da década de $\mathbf{8 0}$ aumentaram as exigências dos credores internacionais, obrigando o país a reorientar sua economia para a geração de crescentes saldos da balança comercial.

A situação se exacerba nos anos 80 , com as transferências financeiras para o exterior na contra-mão das necessidades da economia brasileira. Entre 1985 e 1990 o Brasil pagou a soma de US\$ 56.9 bilhóes a título de juros; entre $1983 \mathrm{e}$ 1993 foram recambiados cerca de US\$213.8 bilhöes na forma de juros e amortizações.

A estrutura montada para exportação redundou na desarticulação de setores vitais da economia voltados para o mercado interno e na sangria de recursos públicos em visível detrimento da açáo do Estado direcionada ao atendimento de necessidades sociais básicas. Os superávits comerciais, que teriam de ser convertidos para a moeda nacional, provocaram pressóes sobre a base monetária, impondo a emissão de títulos públicos a juros elevados e originando uma cultura especulativa que ficou conhecida por ciranda financeira. A rolagem da dívida externa e sua internalização e estatização comprometeram fortemente as finanças públicas federais e funcionaram como elemento propagador da inflação. 
O ajustamento da economia brasileira diante da crise originada desde o final dos anos 70, até o presente, teve por conduta central o giro das dívidas interna e externa e a política de combate à inflação com a permanência combinada de elevadas taxas de juros e erosão salarial. Com isso, o setor financeiro firmou-se como destacado espaço de valorização para o capital em geral. Dá-se uma transmigração profunda da economia, da esfera produtiva para a esfera especulativa, ao lado do privilegiamento de atividades geradoras de divisas beneficiadas pela relação câmbio/salário. $O$ sistema financeiro e bancário passa a existir preponderantemente em função da política estatal de juros elevados e de ganhos com a inflaçáo.

Dentro desse espectro, a crise fiscal do Estado assume contornos que se revelaram na expansão da participaçáo dos serviços das dívidas nas contas orçamentárias do país. Há estimativas que apontavam para o comprometimento de cerca de $65 \%$ do Orçamento da República em 1993, quando era de $25 \%$ em 1991 , e de $45 \%$ em 1992. Apesar do achatamento dos salários dos funcionários públicos, a capacidade de investimento do governo encontra-se praticamente esgotada, inclusive impossibilitando a recuperação da infra-estrutura produtiva (distribuição de energia, estradas, instalaçōes portuárias, armazenagem de produtos agrícolas etc.) e de setores produtivos e de serviços estatais e paraestatais. Ao mesmo tempo, a valorização especulativa patrocinada pelo Estado, funcionando como desestímulo ao investimento privado, tem favorecido a elevação de preços exercida através de aumento da margem de lucro como forma de compensar perdas de escala produtiva e de reforçar o autofinanciamento das empresas. A política tarifária também contribuiu para o crescimento da inflação.

Em nível mais geral, as conseqüências do ajustamento da economia brasileira se fizeram sentir com a expansão de segmentos dos setores primário e industrial voltados para a exportação e com o fortalecimento de núcleos oligopólicos e oligopsônicos da economia que ajustaram suas estruturas competitivas ao modelo econômico da crise do Estado. Tal ajustamento implicou avanço no processo de financeirização das empresas, que passaram a se autofinanciar, a apresentar lucros não-operacionais expressivos e a contrair a escala de produçáo e a linha de produtos. Como consequiência da menor escala produtiva, as elevaçóes de custos foram repassadas aos preços. Paralelamente, ocorreu crescimento de produtividade em alguns setores da indústria.

A crescente financeirização da economia foi responsável pelo desenvolvimento de uma cultura especulativa, ao mesmo tempo que a indexaçáo permitiu a correção monetária sistemática de ativos financeiros e patrimoniais, em detrimento dos salários, estabelecendo drástica reconcentração da renda, à qual já se fez referência. $O$ estreitamento do mercado consumidor de bens de salário tornou-se expressāo inequívoca da excludência de um modelo que privilegia a expansão das exportaçóes e de mercados compatíveis com o consumo das classes de 
renda elevada. E, ao lado, assistiu-se a quebra dos sistemas públicos de educação e saúde, e a inoperância do Estado com relação ao saneamento e à preservação ambiental, com graves implicaçôes sobre a saúde pública. A questão crucial da inclusão econômica, social e política na modernidade ética de parcela expressiva dos marginalizados ficou fora da agenda das elites brasileiras. O Estado tornou-se refém das elites, cuja ação dilapidadora tem se revelado no montante das dívidas interna e externa.

Em resumo, os aspectos perversos do ajustamento traduzem-se num conjunto de efeitos que revelam um quadro nacional reverso da integração, por se caracterizar pela exclusão, expresso por:

- crescimento insuficiente da produção de alimentos;

- redução drástica do poder de compra dos salários;

- degradação dos serviços públicos de primeira necessidade, afetando principalmente educação e saúde;

- crescente marginalização econômica, social, política e cultural, abrangendo ampla parcela da sociedade e assumindo contornos de nítido apartheid social;

- aumento do número de desempregados, subempregados e trabalhadores por conta própria;

- fome tornando-se o problema mais drástico em nível nacional;

- desestruturação do Estado e conseqüente emergência de formas crescentes e diversificadas de violência organizada e de impunidade;

- crescente influência da midia nas formas de moldagem da vontade política da população aos interesses das classes dominantes;

- apatia e desinteresse de participação de amplos setores, inclusive e principalmente da juventude, estudantes e trabalhadores;

- disseminação da desqualificação da política e dos políticos, com forte apelo moral, centrado na temática da corrupção; e

- perda do sentido de perspectiva histórica e de um projeto de Nação embasado na democracia, substituído por uma visão conjuntural, de curto prazo, com o imediatismo reforçado pelo cotidiano da subsistência e da violência.

Como se torna evidente, é no modelo macro que se deve buscar as causas geradoras e ampliadoras de diferenças e excludência sociais. Nesse sentido, não adian- 
ta empreender políticas sociais compensatórias, porque implicam agir no varejo, com custos elevados de ineficácia, enquanto a ação desintegradora se efetiva no atacado.

\section{Projetos e perspectivas para o país}

O panorama geral da crise dos anos 80 colocou o país perante duas concepções de conduta econômica e política. Uma, articulada em termos da inserção competitiva na ordem econômica internacional, visando a romper com o quadro de uma economia relativamente fechada, reflexa do modelo de substituição de importaçōes. Abrange concepção direcionada para liberação cambial e política monetária fundamentada em algum tipo de controle exógeno ao Estado, com autonomia do Banco Central. Implica desvencilhamento, através de privatizaçóes, do peso das instituiçóes públicas e privadas do Estado que foram atoladas enquanto receptáculo de endividamento internacional e de estruturas que representam o núcleo de comprometimento crescente dos recursos públicos, como é o caso, por exemplo, do sistema de seguridade social. A concepção em processo procura reverter ainda a descentralização tributária, fruto da Constituição Federal aprovada em 1988. Ao mesmo tempo, sinaliza positivamente com relaçáo ao avanço da financeirização que vem caracterizando a economia mundial através da atração de capitais de risco voláteis, de cunho eminentemente especulativo. Esse aspecto abre perspectiva de amplas flutuaçóes $e$ instabilidades que representam possibilidades de novas crises e exposição das finanças públicas a enormes sobrecargas. É necessário lembrar que o Brasil é um dos países que até aqui menos se adaptou ao modelo responsável pela derrubada da inflação adotado na América Latina, apesar da enorme drenagem de capital para o exterior, responsável pelo exacerbamento da crise financeira do Estado e pelo enorme tributo social pago na década estagnada, com seus efeitos sobre a distribuição de renda e conjugados à crescente excludência.

A outra perspectiva vislumbra a necessária abertura da economia brasileira dentro da ordem econômica internacional. Contudo, com maiores cautelas, a partir de um projeto nacional que contemple políticas industrial, agrária e agrícola, incorporem progresso técnico e recuperem o emprego, atendendo a expansão da oferta de bens de consumo da população de renda menos elevada (política de rendas). $O$ controle da inflação deve passar por um sistema de negociações, partindo do pressuposto de que na sua origem encontra-se um conflito distributivo que se instaurou e se descontrolou a partir da debilitação da instância política e do Estado. Um projeto nacional dessa natureza requer visão estratégica de longo prazo, negociada e compartilhada dentro da gestação de um padrão de confiabilidade entre os agentes, sem exclusão dos trabalhadores. Uma reforma fiscal destinada a fortalecer a confiabilidade do Estado deve considerar a ótica distributivista, que faça incidir os tributos de forma progressiva, principalmente através de tributos sobre a renda e a riqueza, com ênfase sobre a propriedade 
improdutiva. $O$ combate à financeirização internacional, implica filtrar a exposição da economia nacional aos seus aspectos desestabilizadores. Nesse sentido, devem ser assegurados os pressupostos que levem ao crescimento econômico, acompanhados de medidas emergenciais de curto prazo para atacar o quadro crítico de (des)integração social.

Sob qualquer perspectiva agendada, a questão educacional e o problema do analfabetismo aparecem como pressuposto estratégico.

As macroperspectivas que apontam um quadro crítico de (des)integração social, passam a requerer uma abordagem que considere a dimensão da integração territorial.

\section{A crise do Estado e a integração territorial}

A rediscussão da integração territorial requer aprofundamento da concepção e significado de sua inserção dentro das atuais condiçóes de desenvolvimento do capitalismo no Brasil. Nesse sentido, cabe uma análise crítica do papel do Estado na sua ação diante dos chamados desequilibrios regionais. Trata-se de um esforço de reflexão crítica sobre o papel que vêm desempenhando as instituiçóes e agencias governamentais, supostamente voltadas para o desenvolvimento das regiōes. Aspecto importante a ser considerado é sentido do regional se esvanecer perante a nova ordenação territorial dos grandes projetos que emergem de uma economia estagnada em busca de integrar-se à ordem competitiva internacional.

Tanto a economia da regiáo Nordeste quanto a da região Norte têm apresentado recentemente crescimento do PIB mais intenso que o do Brasil (Sudene, s.d.). Esse crescimento tem servido de argumento para supor-se que estaria havendo reversão no quadro das disparidades regionais no país. A explicação do crescimento mais acelerado do PIB do Norte e Nordeste necessita ser evidenciada no quadro da crise econômica nacional. Neste quadro percebe-se que o setor industrial permaneceu relativamente estagnado, e o setor primário, vinculado a exportaçóes e à economia de divisas (energia), foi o responsável pelo crescimento apresentado.

Por outro lado, o crescimento populacional do Norte e Nordeste apresentou maior impacto em nível nacional no tocante à transigáno demográfica por que passa o país, caracterizada pela queda drástica na taxa de natalidade.

Os dois processos assinalados - crescimento do PIB do Norte e Nordeste, e crescimento menos intenso das respectivas populaçóes relativamente ao crescimento da população brasileira -, implicam conjuntamente diminuição da distân- 
cia entre as rendasper capita do Norte e do Nordeste com relação às do Brasil e do Centro-Sul. Este fato pode levar à conclusão equivocada da diminuiçăo das disparidades regionais existentes no país. Vejamos o porquê.

A queda no nível de natalidade decorrente da diminuição da fertilidade feminina e o aumento do PIB são indicadores que, em condiçóes normais, espelhariam uma trajetória de desenvolvimento caracterizada por práticas conscientes de planejamento familiar e pelo crescimento da produção. Contudo, não éo que vem ocorrendo no Norte e Nordeste desde a década de 80. São processos resultantes de um crescimento voltado para fora, com baixos encadeamentos, numa economia estagnada, como já assinalado, e de contenção do crescimento populacional feita de forma obscura e não-planejada.

Em resumo, pretende-se destacar que:

- as regióes traduzem hoje uma realidade integrada aos quadros econômico, social e político nacionais de crise do Estado, nas quais a excludéncia social aparece de forma mais ou menos agudizada;

- as estatísticas dos anos 80 e 90, captam arranjos espacializados da crise e acomodação econômica da estagnação, em que Norte e Nordeste figuram com crescimento não revestido de efeitos internalizáveis para o conjunto de sua população;

- os crescimentos apontados se ajustam à ótica da inserfão competitiva no quadro da economia internacional, sem quaisquer medidas e salvaguardas destinadas a preservar interesses e ajustamentos endógenos de longo prazo;

- o ajustamento da transição demográfica em marcha apresenta ocorrência mais intensa no Norte e Nordeste do que no resto do país. Ressalte-se que esse efeito é irreversível e de longo prazo. Apesar da esterilização feminina vir sendo conduzida fora de qualquer padráo ético e com omissão do Governo (e da Igreja), seus resultados apontam para certo arrefecimento da pressáo futura no tocante ao atendimento de saúde, educação e geração de emprego para a população de menor faixa etária, o que poderá ensejar um potencial de recuperação da até agora crescente dívida social;

- as política econômicas compensatórias (fluxos de renda transferidos para as regiōes mais deprimidas) têm cumprido papel funcional e necessário, em nível nacional, de repor e realimentar os fluxos monetários e de renda que não se traduzem necessariamente em desenvolvimento. Geram efeitos nas áreas mais desenvolvidas através do refinanciamento da perda de substância econômica das áreas mais debilitadas economicamente. São antes necessidades daquelas 
áreas, processo típico das economias capitalistas, no sentido de que os gastos governamentais implicam ampliação da acumulação, e de que esta tende a se concentrar nas áreas de maior densidade de capital. A outra face das políticas compensatórias é a da domesticaçăo política das elites regionais a certos interesses hegemônicos de cunho clientelista/patrimonialista, que atuam reforçando o processo de excludência social; e

- a retomada do crescimento econômico nacional, com recuperação dos investimentos e do crescimento industrial, deverá implicar aumento da distância em termos de margens regionais de crescimento econômico e de renda per capita do resto do país com relação às regiōes mais deprimidas. A retomada do crescimento, apesar de representar melhoria potencial das condições de vida da população nestas áreas, porque as economias do Norte, do Nordeste, do Rio de Janeiro etc. tendem a crescer com o crescimento da economia nacional, não representará de per si mudanças estruturais e qualitativas que imprimam melhor patamar de distribuição de renda, de diminuiçăo da margem de excludência das populações e de fortalecimento político dos trabalhadores nas decisóes econômicas e no encaminhamento dos rumos do desenvolvimento regional.

O esgotamento do modelo de intervenção do Estado até então adotado, atrelado a um padrão de acumulação orientado tanto para a exportação quanto para a produção de bens duráveis e de consumo para as classes de renda elevada, tem por argumento os efeitos excludentes por ele produzidos. Diante disso, impóe-se a necessidade de reorientação econômica que enseje a inclusão dos segmentos marginalizados à modernidade-ética do direito ao trabalho e à distribuição de renda aceitável. O que se deseja destacar é que qualquer análise e roteiro de sistematização para uma ação política, passa pela necessidade da construção da democracia no pósditadura. Implicaria, portanto, colocar no epicentro da análise, e da ação, o papel do Estado na sua relação com a sociedade civil em novos termos.

As formas de relação entre o Estado e certas elites têm, até aqui, levado a formas de não-objetivação da exploração da força-de-trabalho e de negação do desenvolvimento tecnológico. A perda de competitividade tem sido compensada por rebaixamentos salariais. $O$ círculo vicioso resulta sempre na desqualificação do trabalho refletida numa renda per capita declinante e nas estatísticas da fome. É sabido que a acumulaçáo moderna continua primitiva em muitas paragens, onde a apropriação de privilégios a partir do Estado tem se constituído a regra geral. Como afirmou recentemente Werner Baer, ao receber o título de Doutor honoris causa na Universidade Federal do Ceará, "torna-se necessário privatizar o setor privado".

Os quadros regionais, guardadas suas especificidades, permitem entender o real significado de capitalismo de Estado, aprisionado pelas elites, no cerne da crise financeira que esgota o Estado e respalda a estagnaçăo, o desemprego e os baixos 
salários. O regionalismo continua na ordem do dia e tem sido utilizado como a forma mais convincente de obtenção do consenso entre as elites, consenso em que os excluídos continuam servindo de massa de manobra e o risco de desagregação da Federação passa a fazer parte do jogo de aprisionamento do Estado.

A partir da década de 80, o conceito de regiáo tem passado por significativas modificaçóes, diante da nova configuração territorial imposta pelos grandes projetos (Santos Filho, 1989). A nova região decorre da expansão de setores vinculados à política de geração e economia de divisas, com o surgimento de algumas economias de enclave, autonomizadas e vinculadas internacionalmente, com destaque para alguns produtos agrícolas de exportação, de minérios, álcool e petróleo. Isso explica o crescimento recente da economia nordestina, acima da média nacional, sem que tenha se traduzido em melhores condiçóes de vida para a população. As modificações ocorridas na divisão espacial do trabalho do país são específicas de um quadro de economia estagnada.

Nesse sentido, o Nordeste apresenta especificidades históricas e culturais que necessitam melhor qualificação no que diz respeito às intervenções genéricas do Estado e da construção da democracia. A característica marcante dessas especificidades é a de espaço aprisionado pelas relaçôes de poder das oligarquias que perpetuam a baixa produtividade, baixos salários e ganhos dos trabalhadores e elevada parcela de exclusão social. Outra especificidade é o fenômeno da seca, que atua como forma ratificadora da primeira. A presença de ilhas de modernidade e de produtividade não tem contribuído para a eliminação de relaçóes de trabalho arcaicas; tem mantido a estrutura fundiária concentrada, inibidora de acesso à terra para os que desejam trabalhar; e não tem aumentado a oferta de alimentos da região. A modernidade é antes uma ilha para aqueles que usufruem e lucram com o quadro de excludência social.

\section{A democracia como prática política ou novas relaçốes entre Estado e sociedade}

A crise do Estado pode propiciar perspectiva positiva para práticas políticas e sociais que revertam o tratamento tradicional e conservador de apropriação do Estado. Trata-se da construção de proposiçóes de políticas nas quais a economia sirva à sociedade, $\mathrm{e}$ onde as reivindicaçôes da sociedade civil organizada sejam consideradas quando da definição de prioridades da, e para a, maioria da população.

Assim, cabe ao Estado um papel crucial estritamente orientado para desenvolver ações públicas, democraticamente definidas, em espaços setoriais e territoriais nos quais os conflitos políticos e de interesses passem a ser efetiva- 
mente negociados. Tal mudança indica ruptura com a tradição das ações autoritárias, excludentes e centralizadas nas esferas de governo, distanciadas dos reais interessados e que tem sistematicamente impedido o acesso aos programas governamentais dos segmentos de pequenos produtores e da população organizada da sociedade. $O$ desenvolvimento com democracia afigura-se como processo de eliminação de privilégios das elites, de publicização do Estado e da existência de espaço e oportunidades para as açóes que emanem da vontade autônoma de setores organizados por melhores condições de produção e de vida, com garantias políticas e institucionais de atendimento de seus direitos.

O modelo de ações negociadas e compartilhadas mais conhecido, envolvendo iniciativa privada, trabalhadores e governo, é o das Câmaras Setoriais, cujo exemplo marcante deu-se no âmbito da indústria automobilística. No entanto, vêm ocorrendo outras práticas que sinalizam a possibilidade de generalização deste modelo. É o caso das Operações Urbanas longamente maturadas no âmbito da Prefeitura Municipal de São Paulo, e postas em prática a partir da gestão de Luiza Erundina. O caso da Operação Urbana Água Espraiada é elucidativo. Tratava-se de uma área, perto do rio Pinheiros, com 1.337 ha, onde habitavam cerca de 171 mil habitantes, e existiam cerca de 6.500 domicílios favelizados. Parte da área era um fundo de vale, sujeito a inundações do córrego da Água Espraiada. A recuperação da área envolvia basicamente investimentos da ordem de US\$ 400 milhões em drenagem, saneamento, obras viárias, desapropriaçōes e edificação de habitações de interesse popular. Estava prevista a relocalização da população favelada dentro da mesma área. O perímetro da operaçáo e seu conteúdo tornaram-se objeto de lei municipal, a qual previa a implementação de mudanças na legislação do uso do solo, com efeitos de valorização fundiária numa parcela da área passível de negociação com empreendedores imobiliários. Parte do diferencial de valorização deveria ser paga pelos proprietários ou compradores, gerando receita destinada a cobrir proporção expressiva dos custos da Operação Urbana. A outra fonte de receita decorreria da venda subsidiada de domicílios à população favelada. A Operaçáo, desta forma, não requereu qualquer desembolso de recursos públicos por parte da Prefeitura. Amplo campo de negociaçóes envolvendo o município, proprietários, empreendedores imobiliários e associação de moradores legitimou a Operação Urbana, garantindo interesses distintos, através da demarcação legal que amparou as açôes.

A democracia como prática política implica a construção de novas relaçóes entre Estado e sociedade civil. Essas novas relações devem contribuir para desarmar a estrutura e presença onipotente do Estado, garantindo espaço de maior autonomia para negociação entre as partes. O modelo de negociação e compartilhamento é uma diretriz não-rígida e pré-estabelecida, uma vez que o espaço das ações deve conter a criatividade dos agentes, contingenciada a cada realidade singular. 


\section{Nordeste e política social}

As prioridades regionais devem ser necessariamente integradas à política $\mathrm{e}$ às prioridades estratégicas nacionais. Nesse sentido, o Nordeste enfeixa um quadro integrado, porém agudizado, dos constructos políticos, sociais e econômicos que redundaram em regularidade perversa das estatísticas sociais que apontam a escala de excludência. Assim, o regional se desintegrou, sem que as ilhas ensejassem dissimular as médias e medidas mais apuradas da desigualdade, da vida e da morte. Por inspirar a face problemática da integração, o Nordeste, enquanto regional desintegrado, continua emblemático e aponta como forte referencial para o tratamento da integração social. Porém, não como política que tenta assistir aos desajustados e inadaptados do sistema.

A mudança de face do Nordeste dentro de uma diretriz mais efetiva deve ser priorizada a partir do campo como matriz desencadeadora de elevados efeitos para a frente e para trás. Nesse sentido, a Reforma Agrária deverá constituir a principal política estratégica nacional para a região. Desde 1959 (Celso Furtado, 1977), as várias tentativas de açóes voltadas para a reestruturação agrária e a produção agrícola têm sido obstaculizadas pela estrutura de poder no Nordeste. Essa restrição deve ser encarada dentro de uma formulação coerente e adequada que rompa, inclusive, com formas tradicionais adotadas para o equacionamento do problema agrário nordestino, no Semi-Árido e na Zona da Mata.

A implementaçáo de uma política de Reforma Agrária é proposta a partir de açóes negociadas e compartilhadas, aqui denominadas af̧öes territoriais de desenvolvimento democrático, aproveitando o cabedal de saber técnico e ẹngajado acumulado sobre a realidade da regiáo. Deverá reunir distintos interesses, buscando assegurar complementariedade de ações no campo produtivo, de gestão, de participação e cooperação, de extensionismo, de armazenagem e comercialização, de preservaçáo e manejo ecológico-ambiental, de encadeamento produtivo, de formaçáo educacional e de aptidões e garantia de assistência à população envolvida. Os programas da política de Reforma Agrária seráo desenvolvidos com base em diretrizes gerais aplicadas às açóes territoriais de desenvolvimento democrático, considerando especificidades localizadas e formas de participação acordadas entre seus agentes. Essas afōes territoriais deverão ser implementadas dentro de perímetros que tipifiquem sistemas microrregionais coerentes, de interesses econômicos, sociais e políticos, decorrentes ou não de investimentos estatais, de bacias hidrológicas, de áreas contíguas de irrigação, de sistemas edafomorfológicos, de municípios e de outros, dotados de formas de integração intersetorial, contratualmente legalizadas por força de lei, através de soluçóes acordadas e compartilhadas, vinculadas à definição prévia de usos e fontes de recursos. As af̧öes territoriais vinculadas à Reforma Agrária deverăo estar definidas, de acordo com suas singularidades, dentro de normas de zoneamento de uso, exploração e conservação do 
solo, subsolo e recursos naturais, inclusive de controle ambiental, e do processo de desertificação. Em princípio, o Estado não deverá proporcionar ganhos privados de valorização fundiária como decorrência de seus investimentos, notadamente em infra-estrutura. Quandó isso ocorrer os referidos ganhos deverão ser necessariamente recuperados pelo Estado como recursos a serem destinados a açóes localizadas, objetivando garantir sobretudo acesso à terra para quem quer trabalhar e se incorporar às açóes territoriais. Instrumentos do tipo contribuição de melhoria, aperfeiçoamento do Imposto Territorial Rural e aportes financeiros decorrentes da valorização fundiária deverāo constituir forma usual de complementaçáo de recursos para custeio das aģóes.

Na Zona da Mata deverá ser desencadeada a revisão da política de subsídios e de proteçáo do Estado, com o objetivo de redirecionar a atividade produtiva, principalmente para a produção de alimentos. Deverão ser desenvolvidas negociaçóes visando a reordenar espaços produtivos definidos paraaçôes territoriais de Reforma Agrária vinculadas à substituição e à diversificação de culturas, desenvolvimento de formas cooperativas de produção (agroindústrias), armazenagem e comercializaçáo, dotaçóes de infra-estrutura e equipamentos sociais. Deverão ser desenvolvidos instrumentos que estabeleçam condicionalidades relacionadas a crédito, débitos fiscais e dívidas, incluindo-se a desapropriação e arrendamento de áreas. A agricultura canavieira deverá susbsistir em áreas cuja produtividade seja comprovadamente competitiva uma vez que a mesma tem sido responsável pelo subemprego e miséria na Zona da Mata por empregar os trabalhadores durante apenas seis meses por ano nessa atividade.

O Semi-Árido dispõe de estoque de terras férteis inaproveitado, avaliado em mais de dois milhóes de hectares, cujo aproveitamento requer vastos investimentos, notadamente em infra-estrutura hídrica e irrigação. A política de armazenamento, distribuição de água e irrigação deverá ser parte integrante e indissociável da política de Reforma Agrária, dentro dos moldes já citados. As açōes territoriais de Reforma Agrária nas áreas de irrigação poderão privilegiar a grande propriedade explorada por pequenos e médios agricultores, com base em distintas alternativas: vinculação cooperativa, arrendamento com opçáo de compra ou trabalho comunitário.

O Nordeste conta com significativa população de produtores rurais que praticam uma agricultura de base familiar, com padróes tecnológicos de exploração e cultivo distintos e através de relaçóes de produção diferenciadas. Os problemas básicos que afetam esse conjunto de produtores são a dificuldade de acesso à terra e as baixas sustentabilidades econômica e ambiental dos sistemas de produção. As açōes territoriais de Reforma Agrária, nesses casos, deverão estar preponderantemente direcionadas a municípios selecionados onde existam organizaçóes de trabalhadores rurais e prefeituras dinâmicas que possam implementar açóes de 
acesso à terra $\mathrm{e}$ formas cooperativas de produção. Essas af̧óes deverão contemplar apoio à produção agrícola sob a forma de recursos hídricos e irrigação, manejos dos sistemas de produção vegetal em áreas de sequeiro, dos sistemas de produção animal e do manejo ecológico de pragas e doenças; apoio às atividades pós-colheita (beneficiamento e processamento da produçăo); apoio à comercialização e integração com o Programa de Segurança Alimentar (através da aquisiçăo de safra em bases municipais); recuperação e preservação ambiental. As asóes territoriauis de Reforma Agrária voltadas para produtores que praticam agricultura de base familiar poderão atingir, numa primeira fase, de 5 a $10 \%$ dos municípios nordestinos, conjugando um esforço integrado de centros de pesquisa, universidades, prefeituras, organizaçóes de trabalhadores rurais, organizaçōes não-governamentais, igreja, governos estaduais e agentes financiadores, a serem financiadas principalmente com recursos do FNE e mesmo de agências internacionais. Essas agóes territoriais de Reforma Agrária deveráo ser responsáveis pelo desencadeamento de uma perspectiva politizante de desenvolvimento local, deslocando o tradicionalismo patrimonialista das elites consumidoras de impostos. Considerando que a base económica da grande maioria desses municípios ainda é a agricultura, avalia-se que a base social capaz de iniciar um ciclo de desenvolvimento local seja constituída por trabalhadores rurais, incluindo-se famílias de agricultores que já detêm a propriedade da terra.

O modelo de açöes territoriais de desenvolvimento democrático em bases negociadas e compartilhadas poderá ser ampliado para o desenvolvimento de outros setores, com destaque para o turismo. A ênfase atual de aproveitamento turístico da costa nordestina defronta-se com um espaço de elevada debilidade de padróes de preservaçáo ambiental e cultural de populaçóes nativas. Deveráo ser implementados esforços institucionalizados de zoneamento do uso e ocupação do solo para finalidades turísticas compatíveis com as normas relativas ao gerenciamento costeiro. Os mesmos pressupostos de valorização imobiliária decorrentes dos investimentos públicos, notadamente em infra-estrutura, devem se aplicar às ações voltadas para o turismo. Uma ação complementar refere-se à criaçáo de programas profissionalizantes de pessoal, vinculado a serviços turísticos básicos, envolvendo governos estaduais, municipais e iniciativa privada.

\section{Gestão do desenvolvimento regional democrático}

Constata-se elevado grau de esclerosamento organizacional das instituiçóes e agências governamentais que atuam na região, com perda de rumo, desvios de função, comprometimento com interesses de grupos dominantes, que utilizam as instituiçóes em benefício próprio. É necessário redirecionar o papel dessas instituições. Trata-se de uma refundação, visualizada como um movimento de desenvolvimento institucional público e democrático, centrado no cidadão, e não nas 
elites como tem sido até agora. Isto requer uma nova forma de governar e gerenciar dentro de mudanças dotadas de uma dimensão eminentemente nacional. Deve-se instaurar uma cultura não-excludente, forjada no âmbito das relações que envolvem os interesses públicos, sociais e privados.

Em nível institucional as agências governamentais, bem como as esferas de governo, deverão integrar-se a diretrizes descentralizadoras e flexíveis de açóes democráticas, negociadas e compartilhadas, voltadas para o desenvolvimento regional.

O padrão de intervenção no Nordeste deverá exigir completa reorientação de conduta das instituiçóes e agências governamentais envolvidas com o desenvolvimento regional. Nessa direção, apontam-se como premissas:

- revisão institucional de seu caráter e abertura de canais para torná-las verdadeiramente públicas;

- estímulos ao aprofundamento da democracia interna no modus operandi de cada uma;

- estruturação institucional flexível, voltada para a participação compartilhada, envolvendo esferas de poder público, sociedade civil organizada e iniciativa privada com base em experiências já acumuladas em administraçóes públicas no país;

- novas modalidades de financiamento integrado para o desenvolvimento econômico e social, resultantes de relaçóes compartilhadas entre esferas de governo, iniciativa privada e cidadãos, principalmente onde as negociaçóes entre os agentes tenham sido bem-sucedidas. Economias de escala efetivas deveráo decorrer dessas iniciativas, tanto para os agentes de planejamento e financiamento do desenvolvimento quanto para os contratantes.

As instituições e agências deverão ser reorientadas a partir de diretrizes gerais de desenvolvimento regional, sendo estas integrantes da estratégia nacional de reforma do Estado.

Dentro dessas diretrizes, a definição de prioridades deve contemplar:

- retomada do crescimento econômico com distribuição de renda e de benefícios;

- objetivação de uma estrutura institucional leve, flexível e capacitada, voltada para o planejamento regional e de um programa operacional de financiamento e gestão com base em princípios democráticos, públicos e não excludentes;

- estruturação e implantação da regionalizaçáo do orçamento anual e plurianual, bem como acompanhamento e controle de sua execução. 
Os estados e municípios deverão estar tecnicamente prepararados para assumir maior envolvimento no planejamento, gestão e extensão dos programas, e açóes voltadas para o desenvolvimento, inclusive buscando formas adequadas no plano institucional e de financiamento.

Quanto ao financiamento do desenvolvimento regional, este deverá ser objetivado em função de ajustes macroeconômicos que ensejem a recuperação da capacidade de investimento do Estado. Dentre esses incluem-se alongamento do perfil da dívida interna, rebaixamento da taxa de juros e reforma fiscal que reforce a margem de poupança pública, garantindo recursos orçamentários. Adicionalmente, a combinação de mecanismos de incentivos fiscais e crédito bancário de curto e longo prazos poderão ser complementados por participação acionária de recursos públicos, investimentos da iniciativa privada e recuperação de benefícios privados gerados por obras públicas.

Os atuais mecanismos de crédito, financiamento, subsídios, bem como os Fundos (Finor e FNE), têm de ser reorientados para atender aos princípios e diretrizes de desenvolvimento regional democraticamente definidos. Ao mesmo tempo deverão ser criadas formas de controle administrativo, de natureza política e social, sobre seus organismos gestores. Tal controle deverá ser respaldado por uma proposta mais ampla, em nível nacional, de formulação de um Código de Processamento Administrativo Democrático - Cpad. Esse Código deverá configurar um instrumento ágil que introduza garantias de direitos do cidadão sobre os atos administrativos que emanem do Estado.

A política de investimentos para o Nordeste terá que passar por completa revisão de concepção e forma operacionais. Tal revisão não implica necessariamente em modificação profunda dos mecanismos e instrumentos existentes. Deverá, porém, recolocá-los dentro de diretrizes mais amplas de desenvolvimento regional, procurando enquadrar os interesses privados dentro de uma ótica compartilhada, na qual os benefícios privados sejam negociados com o Estado tendo em vista a geraçáo de benefícios sociais acordados e comprometidos. O Estado deverá deixar de ser gerador institucional de benefícios privados desvinculados dos interesses públicos. Os subsídios - que atendem sempre ao interesse do capital - deverão estar vinculados a contrapartidas e condicionalidades de atendimento de interesses públicos.

Notas

1 Os aspectos empíricos relativos à transição demográfica não são aqui apresentados. Para isso, ver Roberto Smith \& Ácio A. Oliveira, Brasil: integrafão social e equalizajẫo de oportunidades? p. 2-11. Trabalho apresentado no Seminário Integração social desafio dos anos 90. Recife/PE, 13 e 14 de outubro de 1994. 
2 A importância relativa da fonte de renda denominada Outras rendas na Pnad, que inclui rendimento médio mensal de aplicações financeiras, situa-se entre 2,27\% (1981) e 1,66\% (1990). Vide Atlas da desigualdade: a década de 80. Ipea, 1993.

\section{Referências bibliográficas}

CAMARANO, A. A., BELTRÃO, K. I. \& NEUPERT, R. Século XXI, a quantus andará a populaçāo brasileira? Textos para a discussão, n. 5, Iplan-Ipea, Brasília, 1989.

CARLEIAL, L.M.F. Observaföes sobre a concepfäo de integracão do mercado de trabalbo no Brasil. Fortaleza, Caen-UFC, 1989.

DINIZ, Clélio Campolina \& LEMOS, Maurício Borges. Dinâmica regional e suas perspectivas no Brasil. In: Prioridades e perspectioas de politicas públicas para a década de 90. Brasília, Ipea-Iplan, 1990.

FURTADO, Celso. Uma política de desenvolvimento econômico para o Nordeste. Grupo de trabalho para o desenvolvimento do Nordeste (GTDN). In: Formacão económica do Brasil - a experiência da industrializagcão, org. Versiani, Flávio Rabelo \& Mendonça de Barros, José Roberto, série Anpec, São Paulo, Saraiva, 1977, p. 293-338.

NORDESTE INDICADORES. Fundação Instituto de Planejamento do Ceará, Iplance, Fortaleza, 1995.

OLIVEIRA, Francisco de. Elegia para uma re(li)giāo. Rio de Janeiro, Paz e Terra, 1977.

SALM, C. et al. O mercado de trabalho brasileiro: estrutura e conjuntura. Rio de Janeiro, MTb/IEI/Ufrj, 1987.

SANTOS FILHO, Milton. Notas sobre as redefiniçóes do sistema produtivo e transformações regionais. In: Transformajóes na divisāo inter-regional do trabalho no Brasil. Carleial \& Nabuco (orgs.). Anpec, Caen, Cedeplar, 1989.

SMITH, Roberto. Estagnação e territorialidade. In: Revista Espago \& Debates, Ano XI, n. 32, Núcleo de Estudos Regionais e Urbanos, São Paulo, 1991, p. 57-62.

\section{Resumo}

Este artigo tem como ponto de partida a constatação de dois fenômenos atuais: a transição demográfica e o padrão crítico da distribuição de renda do Brasil. $\mathrm{O}$ argumento central nele contido situa o fortalecimento, ou não, das relaçóos entre o Estado e a sociedade civil, num contexto em que a globalizaçáo passa a impor distintas diretrizes políticas no tratamento da questão social. Ao abordar a questão da integração social e territorial, num quadro caracterizado pela excludéncia social, a tese básica é a dé que a dimensão social deve estar inserida no conjunto das macropolíticas do país, principalmente as de establização. Enquanto a questão estiver afeta apenas às políticas compensatórias dará margem a falsos argumentos de descaminhos entre meios e fins, com 
elevados custos de ineficácia. Nesse sentido, apresentar-se-á neste trabalho algumas formas de encaminhamento na direção da construção democrática, envolvendo as relaçôes entre Estado e sociedade. Como alternativa ao projeto de inserção competitiva, atualmente em andamento, propóe-se a abertura da economia com base em um projeto nacional, no qual as ações públicas sejam democraticamente definidas. Isso significa a eliminação de privilégios das elites e a abertura de canais efetivos com movimento social organizado, que possibilitem a publicização e quebra da onipotência do Estado.

\begin{abstract}
This article begins with the observation of two current phenomena: demographic change and the critical pattern of income distribution in Brazil. It's principal argument concerns the question of strengthening the relationship between the State and civil society in a context where globalization comes to impose distinct political directives on the treatment of the social problem. In dealing with the social and territorial integration question, which is strongly characterized by social exclusion, the basic thesis is that the social dimension must be introduced into the country's set of macro-politics, especially those related to stabilization. As long as treatment of the question is limited to only compensatory policies, there will be room for false arguments regarding means and ends, and resulting high inefficiency costs. The paper presents some ways of moving towards democratic construction which involve the relationship between State and society. As an alternative to the competitive entry project presently underway, it proposes economic overture based on a national project in which public actions are democratically defined. This implies the elimination of the elite's privileges and the opening of effective channels with the organized social movement which would permit publicization and a rupture to State omnipotence.
\end{abstract}

Roberto Smith é doutor em Economia pela USP, professor do Departamento de Teoria Econômica da Universidade Federal do Ceará, onde leciona Formação Econômica do Brasil e Economia Política e autor do livro Formação da propriedade da terra e transifão: um estudo da formagăo da propriedade da terra na transigão para o capitalismo no Brasil, (São Paulo, Brasiliense, 1989).

Aécio Alves de Oliveira é mestre em Economia e professor do Departamento de Teoria Econômica da Universidade Federal do Ceará, onde leciona Economia Política e Introdução à Economia.

Trabalho apresentado no seminário Integracãa social: desafios dos anos 90 , promovido pelo Ministério das Relaçóes Exteriores, no período de 13 a 14 de outubro de 1994, em Recife, para preparação da participação brasileira na reunião de Cúpula das Naçóes Unidas sobre Desenvolvimento Social, realizado em Copenhagen, Dinamarca, em março de 1995. 